\title{
Application of MCDM in the Earlier Stages of the PDP
}

\author{
José Roberto LOBO, Anderson Luis SZEJKA ${ }^{1}$ Eduardo ROCHA LOURES and Osiris \\ CANCIGLIERI JUNIOR \\ Industrial and Systems Engineering Graduate Program (PPGEPS), Pontifical Catholic \\ University of Paraná, Curtiba, Brazil
}

\begin{abstract}
The market demands have pushed the industries to create products to be more innovative and with less time to launch. This situation pressures the entire product life cycle, from its design and manufacturing to the delivery to the market, requiring greater speed and precision in each of these phases. The first stage of the cycle affected by this trend is the development of new products, an interactive, complex engineering and decision-making process. In this sense, it is necessary to know the main agents and actors involved in this process of developing new products and how they interact with each other so that, with this understanding, it is possible to determine the main uncertainties to be mitigated within the earlier stages and avoid potential risk for the subsequent phases of the PDP. By using the PROMETHEE (Preference Ranking Organization Method for Enrichment Evaluation) and GAIA (Geometrical Analysis for Interactive Aid) methods, this paper proposes a comparative model selecting the main components of the product development process, indicating how the interaction between them may minimize the uncertainties in the earlier stages of the PDP.
\end{abstract}

Keywords. Product Development Process, Multiple Criteria Decision Making, Impact Analysis, Agents

\section{Introduction}

The product development process (PDP) can be thought of as a comprehensive and continuous process, where the project is progressively detailed through a series of phases, many of them interdependent with each other and with a high volume of information generated throughout the process. In addition, as development progresses and consolidates, changes become more difficult, from the point of view of costs, reallocation of resources, impacts on schedule among others. Thus, agents and assumptions adopted early in the development phases are critical to the success of the project, determining the direction of the project [1].

The activity of pondering and selecting from a myriad of agents which will be the most impacting and determinant for the success of the work, depends on project to project and under what conditions they will be executed. As selection and evaluation of these agents may have a degree of subjectivity and uncertainties involved, decisionmakers often need assistance in selecting the most satisfactory alternatives. Thus, an effective knowledge and an early evaluation of these agents, with their uncertainties and impacts, become essential elements for the sequence in the execution of new

\footnotetext{
${ }^{1}$ Corresponding Author, Mail: anderson.szejka@pucpr.br.
} 
product development projects. Once these agents are not effectively identified and addressed, they can lead the project to delays, failures, budget compromise and profitability, and often until cancellation. On the other hand, determining agents that are keys to success, and potentializing their applications, can bring powerful competitive advantages. It is important to emphasize that early evaluations do not replace the subsequent project risk management with the applicable tools. It is also observed that there is a detachment of the final stages of the development cycle (prototyping, testing, simulation and optimization) for the initial stages (product definition, product planning, conceptual design), in which the work takes place in levels of abstraction. A number of studies and experiences motivates this shift, according to which decisions taken in the early stages of product development are those that produce the greatest impacts on total cost and product quality. For example, according to Nordlund's (1996) survey, about $80 \%$ of the total cost of a product is defined by the end of the conceptual design step [2].

According to [3], product development is a deliberate business process involving hundreds of decisions, from the generation and selection of ideas to commercialization, and one of the critical steps in this process is the conceptual design of the product being created. In [4], the authors state that approximately $85 \%$ of problems with new products can be attributed to a poor design. Therefore, nothing is more sensible than seeking optimization in this conceptual phase of the product, which involves identifying agents of greater relevance for decision making, how they relate to each other (interactions) and, consequently, impact on success from the project. Some of these agents may have non-measurable goals, such as reducing complexity or increasing adherence to project requirements (qualitative requirements). Situations such as these lead to the existence of links between decision data for the main solutions to be adopted. Determining how to qualitatively analyze the interactions between decision makers and to address combined actions of the main solutions is a problem that must be solved. Thus, this research applies multicriteria decision making method to determine uncertainties and impacts among the main agents involved in the earlier stages of the Product Development Process. Given that products will tend to be designed with higher quality and lower costs, it is expected that society's needs and desires will be met more effectively and promptly.

\section{Technological Background}

Among these various MDCM methods, the MAUT (Multi-Attribute Utility Theory), whose main advantage is that it takes into account uncertainty. Has seen heavy applications in economic, financial, actuarial problems, water management, and energy management and problems agricultural activities. A similar method in popularity to MAUT is the AHP (Analytic Hierarchy Process), whose main feature is the use of paired comparisons - pairwise comparisons, which are used both to compare the alternatives with respect to the various criteria and to estimate the weights of the criteria [5].

Another method that has been applied is the Fuzzy Set Theory, which is an extension of classical set theory that "solves many problems relating imprecise and uncertain data" [6]. Fuzzy Theory has been used in applications in the fields of engineering, economics, environment, medical and management.The Data Envelopment Analysis (DEA) uses a linear programming technique to measure the 
relative efficiencies of alternatives [7] and has as one of the main characteristics the possibility of dealing with multiple inputs and outputs.

Another method applied is the ELECTRE, based on the analysis of concordances and that has the advantage of taking into account in the analysis the uncertainties and inaccuracies in the decision-making. ELECTRE has already been used in energy, economy, environment, water management and transportation issues. The TOPSIS (Technique for Order Performance by Similarity to Ideal Solution) method has an approach of identifying an alternative that is closer to the ideal solution and further away from the ideal negative solution in a multidimensional computing space "[8]. TOPSIS has been used in supply chain management and logistics, design, engineering and manufacturing systems, business and marketing management, environmental management, human resources management and water resources management.

Finally, the PROMETHEE (Preference Ranking Organization Method for Enrichment Evaluation) method has become quite popular due to its simpler mathematical properties and ease of use [9]. An important aspect is related to the ease of decision makers to understand the concepts and parameters inherent in the method, which simplifies the preference modeling process and, consequently, increases the effectiveness of the multicriteria method application. PROMETHEE has had much use in environmental management, commercial and financial management, chemical, logistics and transportation, manufacturing and assembly, energy management and agriculture. In function of its ease of application and because it is able to establish standard relations (preference function) between criteria that are not comparable to each other, the PROMETHHE method was the chosen option for the sequence of this work.

\subsection{The Promethee Method}

The methods PROMETHEE I and PROMETHEE II were developed by were developed by [10] and presented for the first time in 1982 at a conference in Canada. Some years later [11] developed the methods PROMETHEE III (ranking based on intervals) and PROMETHEE IV.

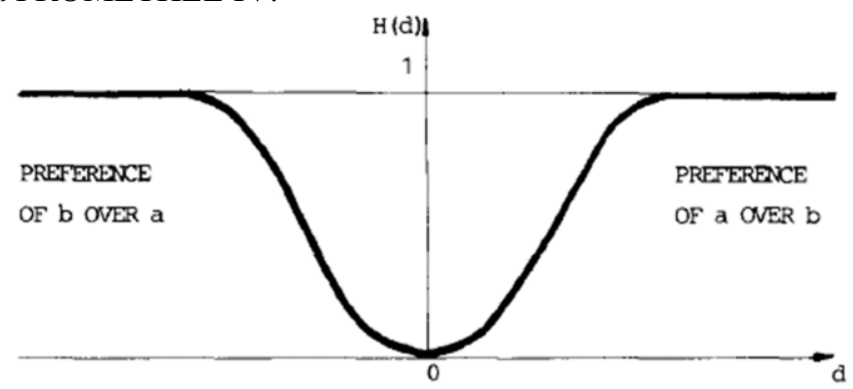

Figure 1. Function of Preference.

In 1992 and 1994, these same researchers also suggested two extensions of the method, PROMETHEE V (MCDM including segmentation constraints) and PROMETHEE VI (a representation of the human brain). The PROMETHEE method is an interactive MCDM approach designed to deal with both quantitative and qualitative criteria with discrete alternatives. In this method, a pairwise comparison is performed to calculate a preference function $\mathrm{H}$ for each criterion, as can be seen in Figure 1. 
Function of Preference. Based on this preference function, a preference index for an alternative "a" over an alternative " $b$ " is determined. This preference index is the measure to support the hypothesis that the "a" alternative is preferred over "b". Thus, the PROMETHEE method can create evaluation standards for alternatives that are not comparable to each other [12].

In a first phase of the method an outbound relationship is constructed between a discrete list of criteria. At this point, a preference index is defined and a preference chart is obtained. In a second phase, based on the graphs of preference, an exploration of each adopted criterion is made: a partial preorder (PROMETHEE I) or a complete preorder (PROMETHEE II) in the set of possible actions, in order to reach the solution of the problem.

\subsection{Criteria for applying the PROMETHEE method}

The PROMETHEE methods can only be applied if the decision maker can express his preference between two actions in a given criterion in a scale ratio:

- The preference function $f \mathrm{j}$ for a criterion $\mathrm{j}$ returns, for a difference $\mathrm{d}$ between two evaluations on this criterion, a value $f \mathrm{j}(\mathrm{d}) \varepsilon[0,1]$. This value is a real value on a ratio scale. Therefore, the decision maker may express the magnitude of his preference between actions of a certain criterion.

- The PROMETHEE methods can only be applied if the decision maker can express his preference between two actions of a criterion in a certain scale:

- The PROMETHEE methods need quantifiable criteria of importance, that is, weights, on a scale of proportion. Therefore, a decision maker should be able to provide such quantitative or qualitative measures with the necessary precision. The decision maker it should also be aware that a criterion with eg 1.8 weight is twice as important as a criterion weighing 0,9 to calculate a value that expresses the outranking ratio.

- The PROMETHEE methods can only be used with criteria where the differences between the evaluations are significant - the preference function, as defined in the PROMETHEE methods, is transforming a difference between two evaluations of a criterion into a real value (between 0 and 1). This is not a problem for criteria with range or ratio scale. For criteria with an ordinal (or nominal) scale, the difference has no mathematical significance.

The partial pre-order PROMETHEE I and the full pre-order PROMETHEE II are based on a global comparison between actions. With this, adding or deleting actions after the construction of the preference function can compromise the overcoming relationship.

\section{Method to determine uncertainties and impacts among the main agents involved in the earlier stages of the Product Development Process}

\subsection{Conceptualization and modeling}

Product design is an iterative, complex, and decision-making engineering process. It usually begins with identifying various needs, proceeds through a sequence of activities 
to find an optimal solution to the problem, and ends with a detailed description of the product. Generally, a development design process consists of three phases: product design specification, conceptual design and detailed design [13][14].

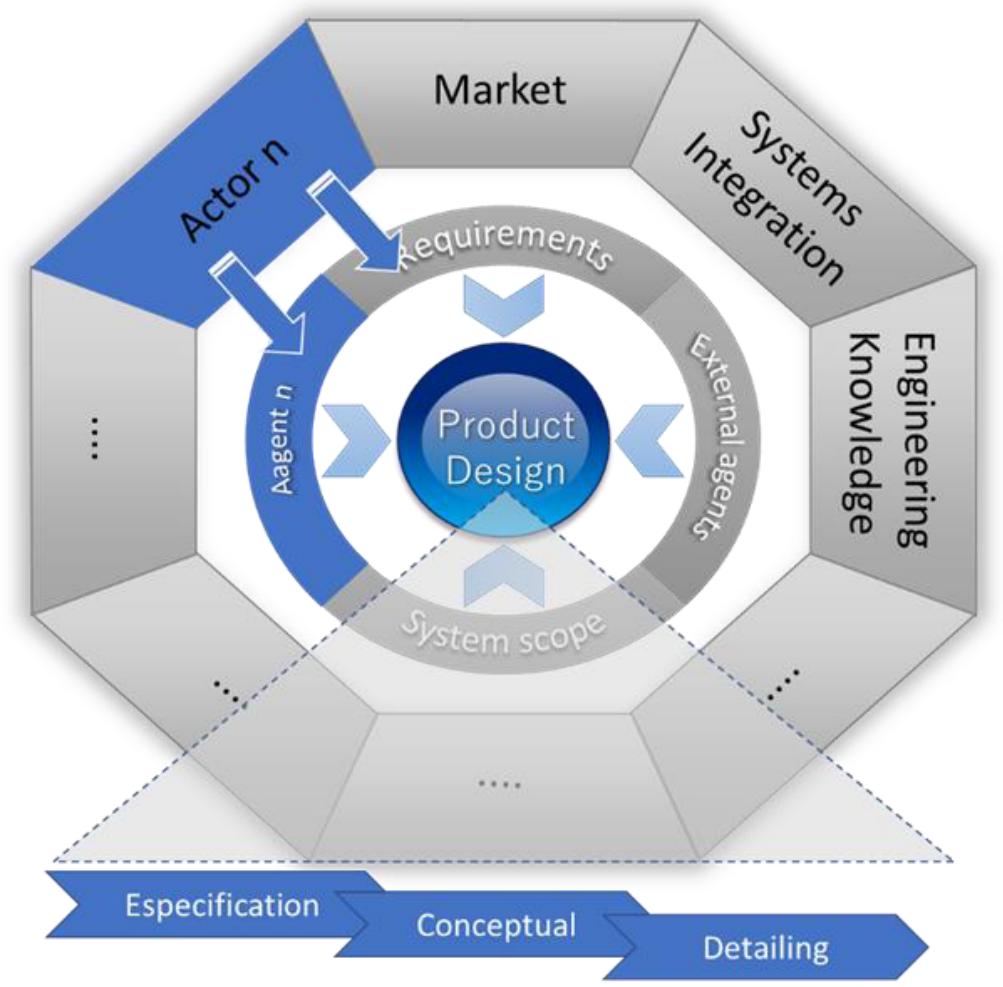

Figure 2. Product Design Model.

During these phases, several agents directly influence the execution of the project, determining priorities, risks, resource allocation and others. Acting on these agents there is the action of several actors, who well determined and controlled will determine the success or failure of the acting of these agents during the project. Figure 2. Product Design Model illustrates how this relationship occurs.

\subsection{Determination of the agents of the development process}

According to [15], requirements statements are written with the various stages of product life in mind and determining the appropriate requirements at each stage. With this, the quality of the product is perceived as all the functional requirements of a product are met.

For simple or complex systems, a basic principle used in analysis is to divide and conquer. This means seizing the entire system, partitioning it into subsystems (components), and then trying to understand each subsystem (component) and its relationships (external and internal) [16]. In this way, factors external to the organization can influence the functional and specific advantages of the project, compromising the organizational implementation capacity and the launching of new products. In addition, since the conceptual design of the product development is 
decomposed into subsystems and components, the agents related to them must be evaluated to understand how they act together (adherence to product requirements).

Exchanging information between dependent and interdependent design tasks can also cause design rework, because downstream starts early using immature information from an upstream task. Therefore, upstream progression could cause downstream rework. [17]. That is, the information relations between all activities in the product development process are perceptible or predictable [18] and result in successive iterations in the various stages of development, which may alter the understanding and the progress of the work already performed.

The project also goes through several tasks: from the clarification of the project objectives, establishing its function, generating alternative incorporation projects that meet these specifications, defining the attributes of the function, evaluating these alternatives and considering the ergonomics and material selection. That is, in the process of product development it is necessary to structure and record how concepts and knowledge must be synthesized in order to support a design situation.

\subsection{Relationship between agents in the development process}

In turn, these agents interact with each other in a non-linear way throughout the development cycle, and their outputs directly influence the performance of the other agents. This interaction is presented in Figure 3.

\section{Interaction between the agents of the project development product}

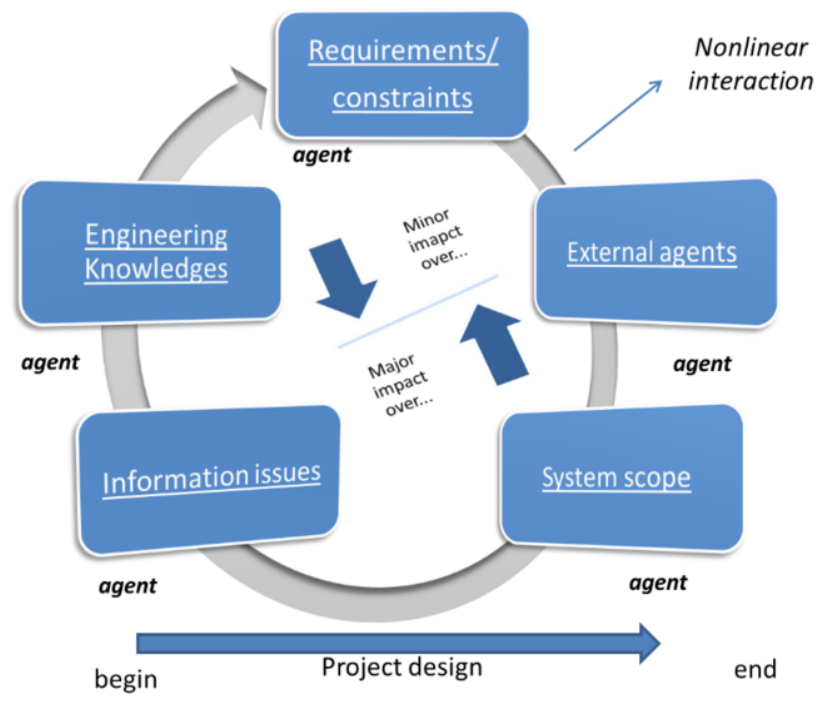

Figure 3. Agents Relationship.

\subsection{Reduction of uncertainties in the development process}

As changes and uncertainties during the development process must be controlled and reduced, it is important that the following design situations be optimized: 
- Requirements changes during the product development project should be minimized to reduce rework over the project scope.

- Influences of external agents should be minimized to keep project complexity in check.

- The decomposition of the subsystems should be organized in such a way as to maximize the adherence of the requirements throughout the development of the project.

- The sharing of the information generated during the execution of the work must be maximized in order to reduce rework or redundancy of efforts and activities.

- The application of Engineering knowledge must be maximized in order to improve the development time of the product in its conceptual phase.

\subsection{Determination of actors in the development process}

These effects of maximization or minimization are caused by the action of the various actors inherent in the development process. For the purpose of the construction of the model that will be proposed, the following actors were considered, which were extracted from the following research: [19], [20],] [21], [17], [22].

- Market: defines the market where the product is inserted. For example: submarine, space, energy, wind etc. [19];

- Initial design phase: related to how decisions taken in the early stages of development [20];

- Decomposition of systems: considers the level of system-wide subsystems [21];

- Integration of systems: related to how the subsystems interact with each other [17];

- System interface: related to how the subsystems interact with each other;

- Project decision making: related to how design decisions are spread across development teams;

- Project information management: related to how information generated during development is managed;

- Uncertainties of design parameters: related to the level of uncertainty of information produced during development [22];

- Engineering Methods: related to engineering knowledge applied during development.

\subsection{Construction of the model}

Considering that the actors are critical success factors for the execution of the development project, it is necessary to determine the degree of their relevance in relation to all agents identified during the development process. Thus, having this construction, it will be possible to determine which actors should be treated in more detail in order to reduce uncertainties throughout the product development project.

Applying these rules in the Promethee method would have the following model, as Figure 4. Promethee Model: 


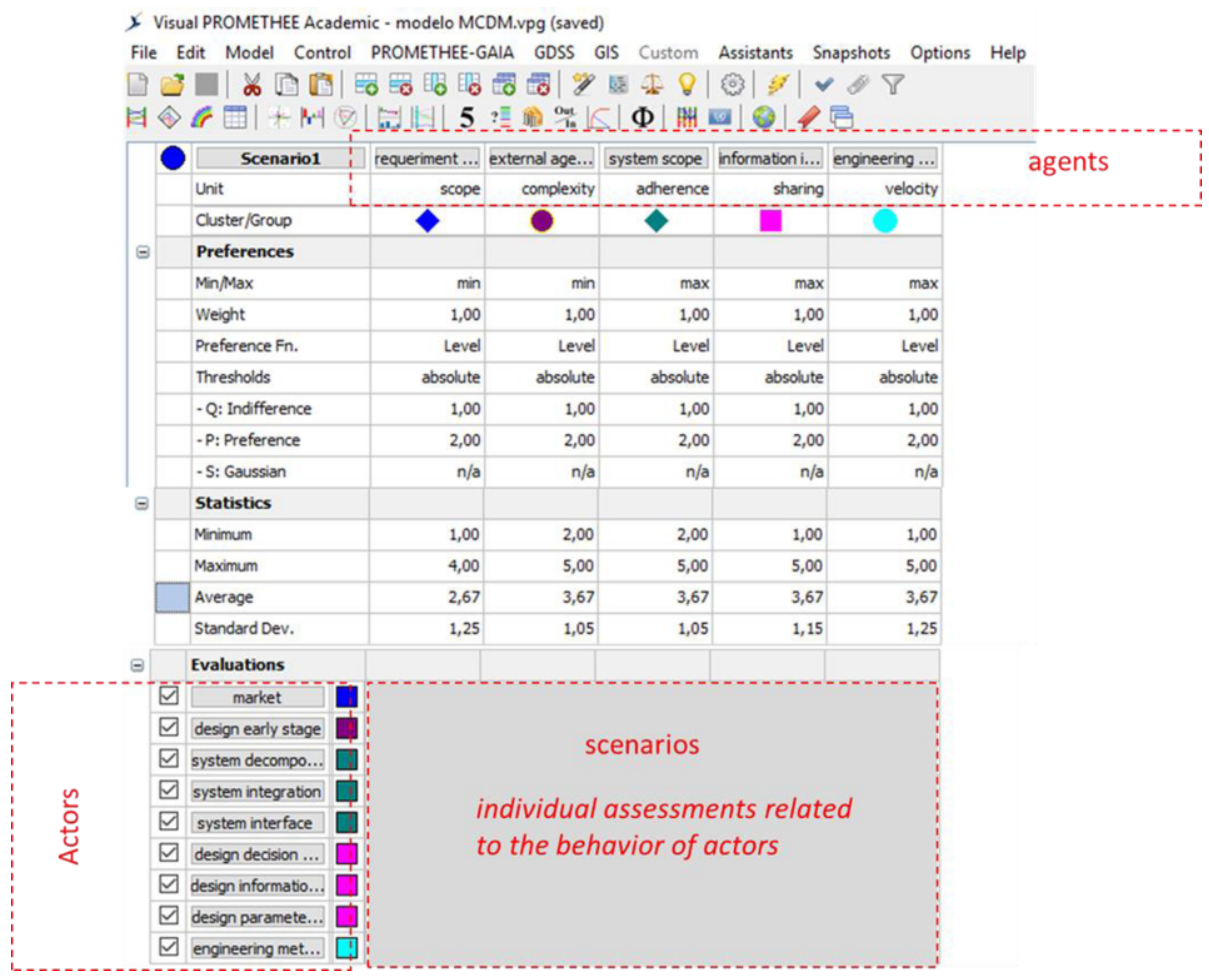

Figure 4. Promethee Model.

\section{Experimentation}

The proposed model was tried in a scenario of development of a product / system of high complexity. Complex products or systems are deployed in a variety of contexts of use, under a large number of different conditions. They also have a behavior that is difficult to predict in some circumstances. Many of these products have a long service life and are upgraded or adapted during their lifetime. They are usually designed by a large number of people, often in different locations and distributed through a large supply chain. Unlike much simpler consumer products, these products typically have only a small number of competing products that can be used as guides for system design [18]. Considering the outlook for the oil and gas industry in the coming decades:

- Exploration of oil and gas happening in more inhospitable regions;

- More people living in cities than in the countryside (more demand for energy);

- Despite recent advances, alternative sources of energy have not fully proven their viability for economic growth, with costs higher than oil;

- High dependence on the petrochemical industry;

- Predicted increase in world oil production for the next 20 years (source: Deloitte Marketpoint World Oil Markets), the evaluation of the behavior of the actors was based on the scenario of development of complex petroleum products in submarine beds. Thus, with these premises, the experimental model was thus constructed, as Figure 5. 
Y. Visual PROMETHEE Academic - modelo MCDM.vpg (saved)

File Edit Model Control PROMETHEE-GAIA GDSS GIS Custom Assistants Snapshots Options Help

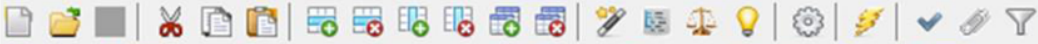

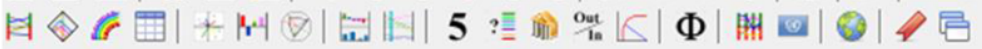

\begin{tabular}{|c|c|c|c|c|c|c|c|}
\hline \multirow{11}{*}{$\Theta$} & & Scenario1 & requeriment ... & external age... & system scope & information $\mathrm{i} . .$. & engineering ... \\
\hline & & Unit & scope & complexity & adherence & sharing & velocity \\
\hline & & Cluster/Group & & & & & \\
\hline & & Preferences & & & & & \\
\hline & & Min/Max & $\min$ & $\min$ & $\max$ & $\max$ & $\max$ \\
\hline & & Weight & 1,00 & 1,00 & 1,00 & 1,00 & 1,00 \\
\hline & & Preference Fn. & Level & Level & Level & Level & Leve \\
\hline & & Thresholds & absolute & absolute & absolute & absolute & absolute \\
\hline & & - Q: Indifference & 1,00 & 1,00 & 1,00 & 1,00 & 1,00 \\
\hline & & - P: Preference & 2,00 & 2,00 & 2,00 & 2,00 & 2,00 \\
\hline & & -S: Gaussian & $\mathrm{n} / \mathrm{a}$ & $\mathrm{n} / \mathrm{a}$ & $\mathrm{n} / \mathrm{a}$ & $\mathrm{n} / \mathrm{a}$ & $\mathrm{n} / \mathrm{a}$ \\
\hline \multirow[t]{5}{*}{$\Theta$} & & Statistics & & & & & \\
\hline & & Minimum & 1,00 & 2,00 & 2,00 & 1,00 & 1,00 \\
\hline & & Maximum & 4,00 & 5,00 & 5,00 & 5,00 & 5,00 \\
\hline & & Average & 2,67 & 3,67 & 3,67 & 3,67 & 3,67 \\
\hline & & Standard Dev. & 1,25 & 1,05 & 1,05 & 1,15 & 1,25 \\
\hline \multirow[t]{10}{*}{$\Theta$} & & \multicolumn{2}{|l|}{ Evaluations } & & & & \\
\hline & $\square$ & market & increase & grow & irrelevant & irrelevant & irrelevant \\
\hline & $\nabla$ & design early stage & highly & decline & strenghten & irrelevant & intensify \\
\hline & $\nabla$ & system decompo... & increase & irrelevant & highly & favor & intensify \\
\hline & $\square$ & system integration & highly & irrelevant & highly & favor & highly intensify \\
\hline & $\square$ & system interface & highly & irrelevant & highly & favor & highly intensify \\
\hline & $\square$ & design decision ... & irrelevant & highly grow & irrelevant & highly favor & irrelevant \\
\hline & $\square$ & design informatio... & irrelevant & highly grow & irrelevant & highly favor & irrelevant \\
\hline & $\square$ & design paramete... & increase & highly grow & weaken & highly prevent & highly diminish \\
\hline & $\square$ & engineering met... & irrelevant & irrelevant & irrelevant & favor & highly intensify \\
\hline
\end{tabular}

Figure 5. Experimental Model.

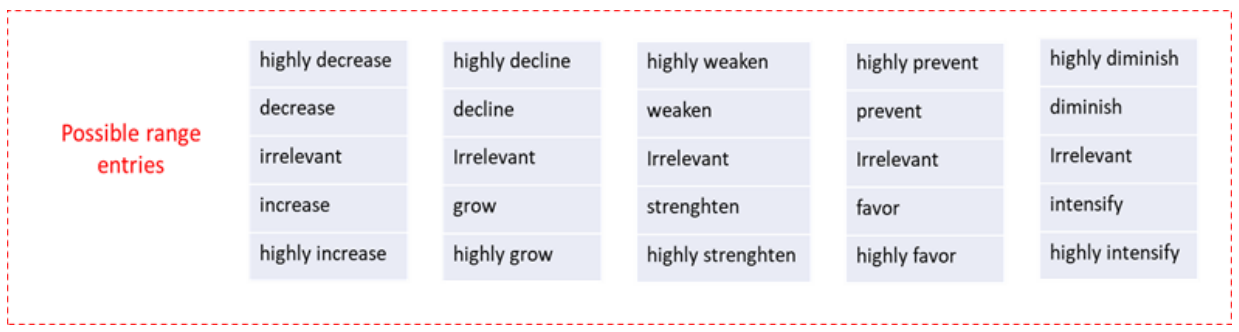

Figure 6. Possible Range Entries.

\section{Discussion of the result}

By applying the method (Figure 7), it is observed that knowing the market where the product is inserted, the actions of project information management and the 
uncertainties of design parameters are of great relevance in the process of product development. In this way, if the effects of these are not mitigated properly, this can jeopardize the success of the development. For the other actors, the deviations are discrete and do not justify specific actions.

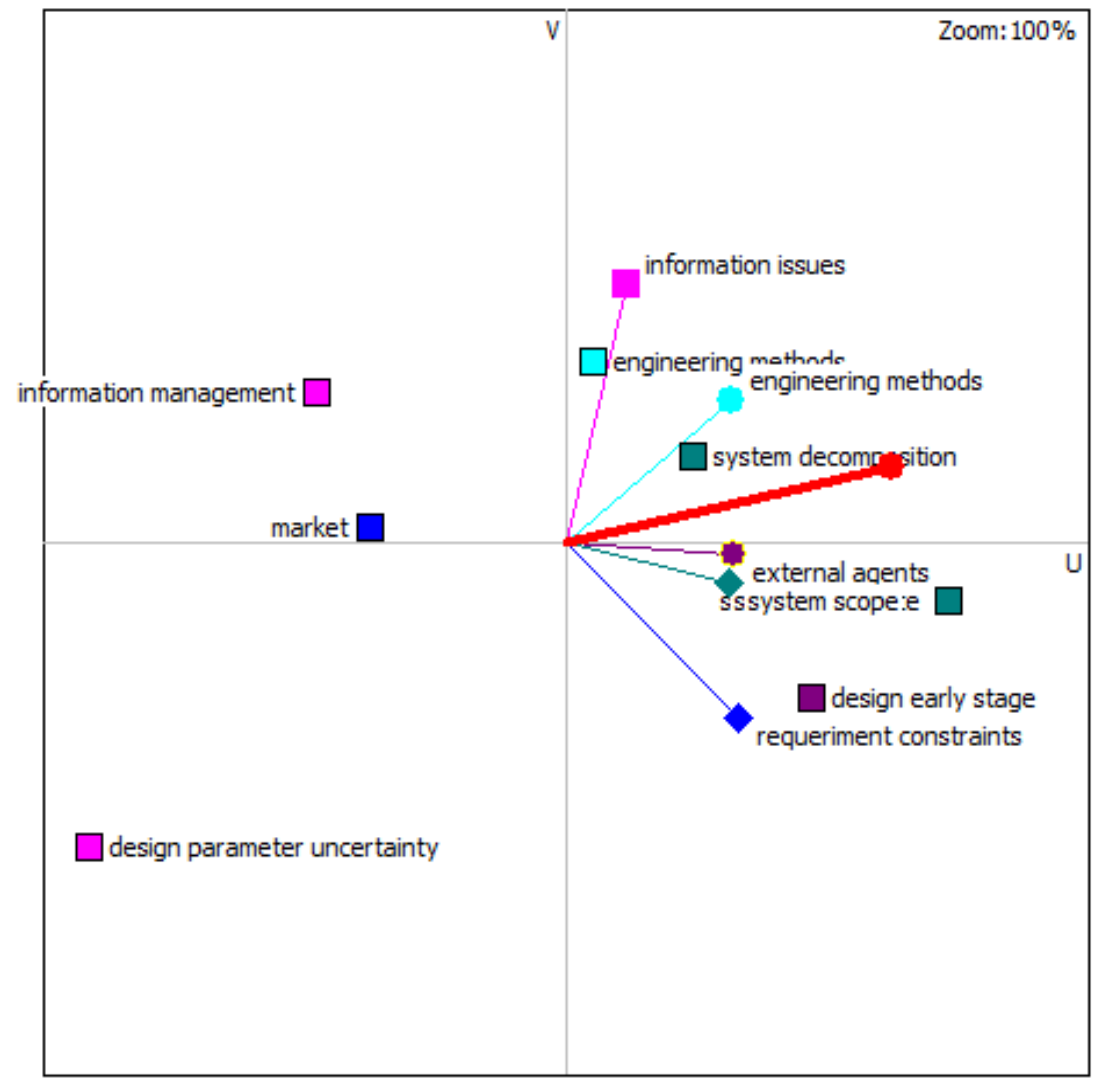

Figure 7. GAIA Analysis.

Considering that in a product development process the number of variables and their possibilities of variation is very large, the proposed model can visually and easily interpret to indicate which of these variables (called here of actors) are those with greater possibility of impact in the development.

It is important to note that there may be variations in the results, given that the model is very dynamic and may vary depending on the market where the product being developed is inserted, the profile and experience of those involved in the ranking of the entries. Therefore, in order to reduce these variations it is recommended that the participants of the evaluation act in the same market and have similar experiences in relation to the product being developed.

The scientific work, involving the application of MDCM methods in the field of product development process, approaches themes with the selection of better design concepts [1], selection of maintenance strategies [23] and selection of materials, designers and manufacturing processes [24]. Thus, the proposed model has a degree of novelty, given that it addresses the identification and mitigation of uncertainties in the development process. 


\section{Conclusions}

The present work aims to propose a model based on MCDM (Multiple-Criteria Decision Making) that helps identify among the main agents of the product development process (PDP), which present the highest degrees of uncertainty and, therefore, must have effective mitigating actions.

In order to reach this goal, a bibliographic review was initially made to identify the main studies and their contributions related to the objectives of the study. The research fields covered the MDCM, Concurrent Engineering, Systems Engineering, Project Management and Risk Management methods. From the compilation of some important concepts, it was possible to create a generic conceptual model that was able to relate the main agents and actors that act in a PDP, and how the interaction between these elements affects the development process.

The great scientific contribution of the present work is its novelty in relation to a great challenge in the process of product development, (aplicable within the Product Engineering disciplines such as Mechanical, Mechatronic, Electronic and Software), which is to identify already in the first phases of the process which elements present the greatest potential of uncertainties, and consequently of risks, for the of the development project. Another important collaboration is that the output of the model will be a reliable input for the risk management of the development project. In addition, because it is a generic model, it can be applied in different markets, for different types of product.

A limitation observed in this construction is related to the accuracy of the results. As it is based on the evaluations of the individuals involved in the process, it is necessary to be judicious in the selection of the contributors for the formation of the data mass. The applicability of the model can be considered as a minor limitation: it is aimed at the development of complex products, involving a large number of variables and difficult predictability of how they will behave throughout the work.

The sequencing of this work provides a link to the risk management of product development projects, as the identified and perceived uncertainties at this stage of development are likely to be potential risks later on. This work also presents another front for future research, related to the management of interfaces between subsystems that composes the development of complex products.

\section{References}

[1] Z. Ayag, An integrated approach to concept evaluation in a new product development. Springer Science+Business Media, pp. 991-1005, 2014.

[2] M.A de Carvalho, Uso dos conceitos fundamentais da triz e do método dos princípios inventivos no desenvolvimento de produto. Third Brazilian Congress of Product Development Management, Florianópolis, SC - 25-27 Setembro de 2001.

[3] V. Krishnan, K. T. Ulrich, Product Development Decisions: A Review of the Literature. Management Science, 2001, vol. 47, pp. 1-21.

[4] D. G. Ullman, The mechanical design process. New York : McGraw-Hill, 1992.

[5] E. Loken, Use of multi-criteria decision analysis methods for energy planning problems. Renewable and Sustainable Energy Reviews, 2007, Vol. 11, no. 7, pp. 1584-1595.

[6] J. Balmat, F. Lafont, R. Maifret, N. Pessel, A decision-making system to maritime risk assessment. Ocean Engineering, 2011, vol. 38, no. 1, pp.171-176.

[7] E. Thanassoulis, M. Kortelainen, R. Allen, Improving envelopment in data envelopment analysis under variable returns to scale. European Journal of Operational Research, 2012, vol. 218, no. 1, pp. 175-185. 
[8] X. Qin, G. Huang, A. Chakma, X. Nie, Q. Lin, A MCDM-based expert system for climate-change impact assessment and adaptation planning - A case study for the Georgia Basin, Canada. Expert Systems with Applications, 2008, vol. 34, no. 3, pp. 2164-2179.

[9] W. De Keyser, P. Peeters. A note on the use of PROMETHEE multicriteria methods. European Journal of Operational Research, 1996, Vol. 89, pp. 457-461.

[10] J.P. Brans, Ph. Vincke, B. Mareschal, How to select and how to rank projects: The PROMETHEE method. European Journal of Operational Research, 1986, Vol. 24, pp. 228-238.

[11] H.-S. Shih, Y.-T. Chang, C.-P. Cheng, A generalized Promethee III with risk preferences on losses and gains. International Journal of Information and Management Sciences, 2016, vol. 27, pp. 117-127.

[12] S. R. Maity, S. Chakraborty, Tool steel material selection using PROMETHEE II method. The International Journal of Advanced Manufacturing Technology, 2015, Vol. 78, no. 9-12, pp. 1537-1547.

[13] N. Wognum, C., Bil, F. Elgh, M. Peruzzini, J. Stjepandić. Transdisciplinary systems engineering: implications, challenges and research agenda, International Journal of Agile Systems and Management, 2019, $12(1)$, pp. 58-89.

[14] W. Hsu, I.M.Y. Woon, Current research in the conceptual design of mechanical products. Comput Aided Des, 1998, 30(5):377-389.

[15] A. Weissman, M. Petrov, S. K. Gupta, A computational framework for authoring and searching product design specifications. Advanced Engineering Informatics, 25 (2011) 516-534.

[16] G. Habchi, C. Barthod, An overall methodology for reliability prediction of mechatronic systems design with industrial application. Reliability Engineerin gand SystemSafety, 155 (2016 )236-254.

[17] P. Arundacahawat, R. Roy, A. Al-Ashaab, An analogy based estimation framework for design rework efforts. Journal of Intelligent Manufacturing, 2011, Vol. 24, pp 625-639.

[18] P.R. Smith, J.A. Morrow. Product development process modeling. Des. Stud., 1999, vol. 20, no. 3, pp. 237-261.

[19] M. Jankovic, C. Eckert, Architecture decisions in different product classes for complex products. Artificial Intelligence for Engineering Design, Analysis and Manufacturing, 2016, pp. 217-234.

[20] D. Woldmichael, F. Hashim, A framework for function-based conceptual design support system. Journal of Engineering, Design and Technology, pp. 250-272, 2011.

[21] U. Yildirim, I. Campean, Development of a structured approach for decomposition of complex systems on a functional basis. Materials Science and Engineering 65 (2014), 012004.

[22] B. Yu, T. Honda, S. Zubair, M. Sharqawy, M. Yang, A maintenance-focused approach to complex system design. Artificial Intelligence for Engineering Design, Analysis and Manufacturing, 2016, pp. 263-276.

[23] M. Shafiee, Architecture decisions in different product classes for complex products. Artificial Intelligence for Engineering Design, Analysis and Manufacturing, 2016, pp 217-234.

[24] C. Marini, N. Fatchurrohman, A. Azhari, S. Suraya, Product Development using QFD, MCDM and the Combination of these Two Methods. Materials Science and Engineering, 2016, 012089. 